\title{
Economic evaluation of vitamin D and calcium food fortification for fracture prevention in Germany
}

\author{
Arne Sandmann ${ }^{1}$, Michael Amling ${ }^{1, *}$, Florian Barvencik', Hans-Helmut König ${ }^{2}$ and \\ Florian Bleibler ${ }^{2}$ \\ 'Department of Osteology and Biomechanics, University Medical Center Hamburg-Eppendorf, Martinistraße 52, \\ D-20246 Hamburg, Germany: ${ }^{2}$ Department of Health Economics and Health Services Research, Hamburg Center for \\ Health Economics, University Medical Center Hamburg-Eppendorf, Hamburg, Germany
}

Submitted 11 May 2015: Final revision received 7 October 2015: Accepted 13 October 2015: First published online 16 November 2015

\begin{abstract}
Objective: The study evaluates the economic benefit of population-wide vitamin D and $\mathrm{Ca}$ food fortification in Germany.

Design: Based on a spreadsheet model, we compared the cost of a population-wide vitamin D and Ca food-fortification programme with the potential cost savings from prevented fractures in the German female population aged 65 years and older.

Setting: The annual burden of disease and the intervention cost were assessed for two scenarios: (i) no food fortification; and (ii) voluntary food fortification with $20 \mu \mathrm{g}$ (800 IU) of cholecalciferol (vitamin $\mathrm{D}_{3}$ ) and $200 \mathrm{mg}$ of $\mathrm{Ca}$. The analysis considered six types of fractures: hip, clinical vertebral, humerus, wrist, other femur and pelvis.

Subjects: Subgroups of the German population defined by age and sex.

Results: The implementation of a vitamin D and Ca food-fortification programme in Germany would lead to annual net cost savings of $€ 315$ million and prevention of 36705 fractures in the target population.

Conclusions: Vitamin D and Ca food fortification is an economically beneficial preventive health strategy that has the potential to reduce the future health burden of osteoporotic fractures in Germany. The implementation of a vitamin D and Ca food-fortification programme should be a high priority for German health policy makers because it offers substantial cost-saving potential for the German health and social care systems.
\end{abstract}

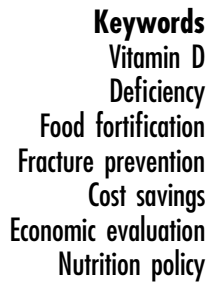

The economic burden of osteoporotic fractures is already large and is likely to increase sharply over the next several decades, especially in developed countries with ageing populations $^{(1,2)}$. Besides these financial implications, osteoporotic fractures also have serious consequences in terms of increased morbidity and mortality and thus have a major impact on patients' quality of life $\mathrm{e}^{(3-5)}$. Osteoporotic fractures are a major health concern that poses a serious financial burden on public health systems, which makes their prevention a central objective for health-care professionals and health policy makers alike.

The risk to suffer from osteoporotic fractures is influenced by serum vitamin D and Ca levels, which are crucial for musculoskeletal health ${ }^{(6)}$. Vitamin D deficiency may lead to osteomalacia, osteoporosis and an increased risk of falls, which in combination contribute to an increased fracture risk ${ }^{(7)}$. Many countries, including Germany, are facing endemic vitamin D deficiency, especially among their elderly populations ${ }^{(8,9)}$. Numerous studies have shown that up to $75 \%$ of the German population has serum 25-hydroxyvitamin D concentration below $20 \mathrm{ng} / \mathrm{ml}$ and up to $65 \%$ of Germany's elderly have Ca intake below the recommended reference value $(1000 \mathrm{mg} / \mathrm{d})^{(10-12)}$.

Increasing a population's vitamin D and $\mathrm{Ca}$ to adequate levels has the demonstrated ability to reduce the incidence of osteoporotic fractures ${ }^{(13)}$. This approach could be a preventive measure to reduce the future health burden of osteoporotic fractures in Germany.

Any of several strategies to increase a population's vitamin $\mathrm{D}$ and Ca levels could be considered, although food fortification is one of the strategies that has already been applied in countries like the USA, the UK and Finland ${ }^{(14-16)} \dagger$ Studies show that food fortification can be effective in improving a population's vitamin D status ${ }^{(17)}$. While this strategy is still generally prohibited in Germany ${ }^{(18,19)}$, recent

†Vitamin D fortification practices include those in the USA (where fortification in milk is mandatory and voluntary in other foods), the UK (where fortification in margarine is mandatory and voluntary in other foods) and Finland (where fortification is mandatory in fat spreads and milk). 
changes in European legislation have opened the window to vitamin D food fortification in Germany and have initiated a debate among German health policy makers about population-wide implementation ${ }^{(20,21)}$.

In addition to the medical efficacy, the economic benefit is a crucial aspect in the evaluation of preventive health strategies, especially in the context of limited health resources. Relatively few studies have investigated the economic benefit of universal vitamin D and Ca supplementation aimed at preventing osteoporotic fractures $^{(22-25)}$. However, to our knowledge, no study has analysed the economic benefit of vitamin D and Ca food fortification as a strategy for primary prevention of osteoporotic fractures in Germany. Therefore the objective of our study was to assess the cost-saving potential of population-wide vitamin D and Ca food fortification based on prevented hip, vertebral and non-vertebral fractures in women aged 65 years and older in Germany. The results of our study will be valuable to health policy makers, who can use the insights gained to evaluate and select an appropriate strategy with which to reduce the future health burden of osteoporotic fractures in Germany. Our study's approach may also serve as a blueprint for similar evaluations in other countries.

\section{Methods}

\section{Analytical framework}

Our model-based study evaluates the economic benefit of population-wide vitamin $\mathrm{D}$ and $\mathrm{Ca}$ food fortification in Germany by comparing the cost of implementing such a programme with the potential cost savings from prevented hip, vertebral and non-vertebral fractures in the female population aged 65 years and older. We assessed two scenarios: (i) no national food-fortification programme, which is the present situation in Germany; and (ii) a voluntary vitamin $\mathrm{D}$ and $\mathrm{Ca}$ food-fortification programme.

While the base year of our analysis was 2014, we expanded our analysis with projections for the years 2025 and 2050 in order to evaluate the influence of demographic changes on the advantages of the strategy. These projections were based on population distribution simulations among various age groups provided by the German Federal Statistical Office ${ }^{(26)}$.

We used a spreadsheet-based model for our analysis that was implemented using Microsoft ${ }^{\circledR}$ Office Excel 2007. A detailed description of the components of our model, the key assumptions and the model data is provided below. The currency used is Euros (€).

\section{Intervention target}

\section{Observation focus}

The incidence of osteoporotic fractures increases significantly in elderly people of both sexes, which makes it a typical age-related disease ${ }^{(27)}$. Based on recent estimates, up to $67 \%$ of these fractures occur in women ${ }^{(1)}$. This makes osteoporotic fractures one of the most likely negative health events for postmenopausal women, which is reflected in a lifetime risk of $40-50 \%{ }^{(28,29)}$. Osteoporosis leads to various types of osteoporotic fracture, with hip, clinical vertebral and humerus fractures accounting for the majority ${ }^{(2)}$. To derive a full estimate of the cost benefit of vitamin D and Ca food fortification, we sought to capture a comprehensive picture of the economic burden of osteoporotic fractures in Germany by including not only hip, clinical vertebral and humerus fractures but also wrist, other femur and pelvis fractures in women aged 65 years and older.

\section{Epidemiological data}

Our model used fracture-specific and age-dependent fracture probabilities for the German female general population (Table 1). The fracture probabilities were calculated in two steps based on the approach of Bleibler et al. $^{(29)}$. In the first step, German population data ${ }^{(26)}$ and hospital discharge data ${ }^{(30)}$ were used to calculate fracture probabilities based on in-patient fracture cases. In the second step, the fracture probabilities obtained were adjusted by age-independent hospitalization probabilities for all fracture types considered in order to incorporate all out-patient fractures in the total fracture probability ${ }^{(29)}$.

Studies have shown that a person's fracture risk differs by residential status (nursing home $v$. communitydwelling) ${ }^{(31,32)}$. To incorporate this effect in our model and obtain relative fracture risks for women who live in a nursing home $v$. those who do not, we adjusted the female general population's fracture probabilities following the approach of Bleibler et al. ${ }^{(29)}$.

Fractures often have severe consequences, especially for patients in higher age groups, such as a persistent reduction in mobility and functional ability, which increase patients' probability to be institutionalized in a nursing home ${ }^{(33,34)}$. To model a fracture-related transition into a nursing home, we used the age- and fracture-specific probabilities of admission to a nursing home estimated by Bleibler et al $^{(29)}$, assuming that the time in a nursing home attributable to the fracture is 1 year. Published research from Bleibler et al. provides additional details on the model input data and their calculation ${ }^{(29)}$.

\section{Cost of fractures}

We adopted a societal perspective for our analysis of fracture-related costs in Germany. However, we did not consider indirect costs because the target group is not of working age and productivity loss is unlikely to be incurred. The base year of our cost evaluation was 2014, and all costs were adjusted for inflation using the harmonized index of consumer prices (HICP) for Germany ${ }^{(35)}$. We distinguished four cost categories in our analysis of fracture-specific direct unit costs: (i) in-patient costs for 
Table 1 Total annual fracture probability of the German female general population by age and fracture type

\begin{tabular}{lcccccc}
\hline Age (years) & Hip & Other femur & Clinical vertebral & Wrist & Humerus & Pelvis \\
\hline $65-69$ & 0.0019 & 0.0003 & 0.0032 & 0.0062 & 0.0027 & 0.0007 \\
$70-74$ & 0.0033 & 0.0005 & 0.0046 & 0.0068 & 0.0036 & 0.0013 \\
$75-79$ & 0.0077 & 0.0010 & 0.0075 & 0.0087 & 0.0053 & 0.0029 \\
$80-84$ & 0.0161 & 0.0016 & 0.0113 & 0.0097 & 0.0072 & 0.0054 \\
$85-89$ & 0.0279 & 0.0026 & 0.0138 & 0.0092 & 0.0087 & 0.0089 \\
$90-94$ & 0.0363 & 0.0032 & 0.0134 & 0.0074 & 0.0086 & 0.0117 \\
$\geq 95$ & 0.0396 & 0.0038 & 0.0105 & 0.0053 & 0.0080 & 0.0112 \\
\hline
\end{tabular}

Table 2 Overview of direct unit costs $(€)$ for German female patients aged 65 years and older by cost category and fracture type

\begin{tabular}{lcccrrr}
\hline Cost category & Hip & Other femur & Clinical vertebral & Wrist & Humerus & Pelvis \\
\hline In-patient & & & & & & \\
$\quad$ Hospital treatment & 8233 & 8061 & 5528 & 3265 & 5402 & 4384 \\
$\quad$ Out-patient aftercare & 1045 & 1045 & 1331 & 850 & 850 & 1045 \\
$\quad$ Rehabilitation & 735 & 735 & 120 & 22 & 192 & 283 \\
Out-patient & - & - & 1750 & 905 & 905 & 1045 \\
Home care & 2358 & 2358 & 2399 & 569 & 1017 & 2358 \\
$\quad$ Professional & 2561 & 2561 & 2187 & 630 & 3211 & 2561 \\
$\quad$ Informal & 27939 & 27939 & 27939 & 27939 & 27939 & 27939 \\
Long-term care & & & & & & \\
\hline
\end{tabular}

patients who required hospitalization included the cost of hospital treatment, out-patient aftercare and rehabilitation after hospitalization; (ii) out-patient costs for patients who required no hospitalization and were treated exclusively in an out-patient setting included costs for medication and out-patient visits to surgeons, physicians and physiotherapy; (iii) home care costs included costs for professional home care and informal home care by the patient's relatives; and (iv) long-term care costs for patients who required institutionalization in a nursing home. An overview of the fracture-specific direct unit costs for female patients is presented in Table 2. Published research from Bleibler et al. contains additional details on the calculations and references ${ }^{(29)}$.

\section{Intervention characteristics}

\section{Intervention strategy}

We analysed voluntary cholecalciferol $\left(\right.$ vitamin $\left.\mathrm{D}_{3}\right)$ and $\mathrm{Ca}$ food fortification of bread as an intervention strategy to reduce the incidence of osteoporotic fractures. Food fortification is an effective measure with which to increase the micronutrient supply on a population-wide basis and minimize the prevalence of deficiencies ${ }^{(36)}$. This strategy is especially practical if the deficiency is widespread across a population, which is the case with vitamin $\mathrm{D}$ in Germany ${ }^{(37)}$. Another benefit of this regulatory approach is that it does not require an active change in consumers' behaviour or food habits ${ }^{(38)}$.

We focused on a voluntary food-fortification programme for two reasons. First, German health policy makers have preferred regulatory interventions that have a voluntary character in comparable cases, such as the fortification of salt with iodine ${ }^{(39)}$. Second, a recent publication by Sandmann et al. showed that the large majority of Germans would be willing to consume vitamin D-fortified products, so mandatory intervention seems unnecessary; we used an adherence level of $82 \%$ for the base case, as determined in the same study ${ }^{(40)}$.

The fortification levels in the base case were set to meet a daily additional intake from fortified food of $20 \mu \mathrm{g}$ (800 IU) of cholecalciferol and $200 \mathrm{mg}$ of Ca. According to the German Osteology governing body's (DVO) guidelines, an additional daily intake of $20 \mu \mathrm{g}$ (800 IU) of cholecalciferol ensures an adequate serum vitamin D level ${ }^{(41)}$, which reduces the risk of osteoporotic fractures $^{(13)}$. The intended risk reduction also requires a sufficient Ca supply in the target population. However, such is not a given in the German female population aged 65 years and older. According to the 2008 National Nutritional Survey, $65 \%$ of elderly women are undersupplied with $\mathrm{Ca}^{(12)}$. An additional daily intake of $200 \mathrm{mg}$ of Ca would compensate for this undersupply, so that the target population meets a total daily Ca intake of $1000 \mathrm{mg}$ as recommended by the DVO, while no other age group exceeds the tolerable upper intake level (UL) of $2500 \mathrm{mg}$ of $\mathrm{Ca} / \mathrm{d}^{(41-43)}$.

Following the recommendation from Brown et al., we selected bread as a suitable carrier for vitamin D and Ca fortification in the German scenario ${ }^{(44)}$, especially as bread shows a homogeneous consumption across the German population and there is no decline in consumption in the elderly population ${ }^{(12)}$. Several studies have confirmed that the fortification of bread is a feasible and practical way to 
Table 3 Amounts of vitamin D (cholecalciferol) and calcium required to achieve target fortification levels

\begin{tabular}{|c|c|c|c|}
\hline Vitamin D & Value & $\mathrm{Ca}$ & Value \\
\hline Estimated loss during flour processing & $15 \%$ & Estimated loss during flour processing & $5 \%$ \\
\hline Amount remaining $(100 \%-15 \%)$ & $85 \%$ & Amount remaining $(100 \%-5 \%)$ & $95 \%$ \\
\hline Estimated loss during bread processing & $30 \%$ & Estimated loss during bread processing & $5 \%$ \\
\hline Amount lost $(85 \% \times 30 \%)$ & $26 \%$ & Amount lost $(95 \% \times 5 \%)$ & $5 \%$ \\
\hline Amount remaining ( $85 \%-26 \%)$ & $59 \%$ & Amount remaining $(95 \%-5 \%)$ & $90 \%$ \\
\hline $\begin{array}{l}\text { Target fortification level per } 100 \mathrm{~g} \text { of bread } \\
(20 \mu \mathrm{g}(800 \mathrm{IU}) / 1.8)\end{array}$ & $11 \cdot 1 \mu \mathrm{g}(444 \mathrm{IU})$ & $\begin{array}{l}\text { Target fortification level per } 100 \mathrm{~g} \text { of bread } \\
(200 \mathrm{mg} / 1 \cdot 8)\end{array}$ & $111 \mathrm{mg}$ \\
\hline $\begin{array}{l}\text { Amount required to achieve target fortification level } \\
(11.1 \mu \mathrm{g}(444 \mathrm{IU}) / 59 \%)\end{array}$ & $18 \cdot 65 \mu \mathrm{g}(746 \mathrm{IU})$ & $\begin{array}{l}\text { Amount required to achieve target fortification level } \\
(111 \mathrm{mg} / 90 \%)\end{array}$ & $123 \mathrm{mg}$ \\
\hline
\end{tabular}

Table 4 Fracture incidence reduction of the vitamin $D$ and calcium intervention for the German female population aged 65 years and older by fracture type and residential status

\begin{tabular}{lccc}
\hline Fracture type & Residential status & $\mathrm{RR}$ & $95 \% \mathrm{Cl}$ \\
\hline Hip & Community dwelling & 0.91 & $0.77,1.09$ \\
& Nursing home & 0.75 & $0.62,0.92$ \\
Other femur & $*$ & 0.86 & $0.78,0.96$ \\
Clinical vertebral & $*$ & 0.89 & $0.74,1.09$ \\
Wrist & $*$ & 0.86 & $0.78,0.96$ \\
Humerus & $*$ & 0.86 & $0.78,0.96$ \\
Pelvis & $*$ & 0.86 & $0.78,0.96$ \\
\hline
\end{tabular}

$\mathrm{RR}$, relative risk.

*Independent of residential status, RR and $95 \% \mathrm{Cl}$ are identical for all non-vertebral fractures.

improve vitamin D and Ca intakes ${ }^{(45-48)}$. Germans consume an average of $180 \mathrm{~g}$ of bread daily ${ }^{(12)}$, so to achieve an additional daily intake of $20 \mu \mathrm{g}$ (800 IU) of cholecalciferol and $200 \mathrm{mg}$ of $\mathrm{Ca}, 100 \mathrm{~g}$ of bread would have to be fortified with $11 \cdot 1 \mu \mathrm{g}$ (444 IU) of cholecalciferol $(1 \cdot 8 \times 11 \cdot 1$ $(444)=20(800))$ and $111 \mathrm{mg}$ of $\mathrm{Ca}(1.8 \times 111=200)$. Bread fortification is carried out during the flour production process by adding the chemical compounds cholecalciferol and $\mathrm{Ca}$. However, because of losses of cholecalciferol $(-41 \%)$ and $\mathrm{Ca}(-10 \%)$ that occur during the flour and bread production processes and storage time, initial fortification levels must be higher than the desired target concentrations in bread ${ }^{(49)}$. The calculations of the initially required amounts of cholecalciferol and Ca are shown in Table 3, which shows that $18.65 \mu \mathrm{g}$ (746 IU) of cholecalciferol and $123 \mathrm{mg}$ of $\mathrm{Ca}$ are required to achieve the target concentration of $11.1 \mu \mathrm{g}$ ( $444 \mathrm{IU}$ ) of cholecalciferol and $111 \mathrm{mg}$ of Ca per $100 \mathrm{~g}$ of bread.

\section{Treatment effect}

Increasing a person's serum vitamin $\mathrm{D}$ and $\mathrm{Ca}$ to adequate levels helps to prevent bone loss and significantly reduces the risk of osteoporotic fractures, especially in high-risk groups like those over 65 years of age ${ }^{(13)}$. The reduction in the risk of fracture that we used in our study was obtained from a Cochrane review from Avenell et al. ${ }^{(13)}$. The risk reduction figures by fracture type and residential status are shown in Table 4.

\section{Intervention cost}

Food-fortification programmes have four general cost categories: (i) recurrent production costs for the ingredients cholecalciferol and $\mathrm{Ca}$; (ii) marketing and education costs for public education and social marketing to raise consumer awareness and ensure their acceptance ${ }^{(40)}$; (iii) food control and monitoring costs for the government's regulatory responsibilities, such as quality assurance, monitoring, legislation and enforcement of fortification regulations; and (iv) other programme-specific recurrent production costs like the cost of capital ${ }^{(50)}$. According to Fiedler et al., the costs of a typical food-fortification programme are distributed as $80 \%$ recurrent production costs, $8 \%$ marketing and education costs, $7 \%$ food control and monitoring costs, and $5 \%$ other programme-specific recurrent production costs ${ }^{(50)}$. The annual costs for cholecalciferol (€0.11 per person at $20 \mu \mathrm{g}(800 \mathrm{IU}) / \mathrm{d})$ and $\mathrm{Ca}$ (€0.22 per person at $200 \mathrm{mg} \mathrm{Ca} / \mathrm{d}$ ) were obtained from leading industry suppliers, and all other programme-related costs were estimated based on the cost distribution from Fiedler et $a l{ }^{(50)}$. As German households throw away about $16 \%$ of the bread they buy ${ }^{(51)}$, we accounted for food waste in our calculations of the annual amount of cholecalciferol and $\mathrm{Ca}$ required. We also accounted for the losses of cholecalciferol $(-41 \%)$ and $\mathrm{Ca}(-10 \%)$ that occur during the flour and bread production processes and storage time in our calculations of the amount of cholecalciferol and $\mathrm{Ca}$ required each year.

\section{Sensitivity analysis}

We conducted seventeen deterministic univariate sensitivity analyses (S1-S17) to assess the impact of singleparameter variations on the benefit-cost ratio (comparison of cost savings $v$. intervention cost) of vitamin $\mathrm{D}$ and $\mathrm{Ca}$ food fortification: (S1) cost of cholecalciferol and $\mathrm{Ca}$ decreased by $-50 \%$; (S2) cost of cholecalciferol and Ca increased by $100 \%$; (S3) cholecalciferol fortification level decreased to $12.5 \mu \mathrm{g}$ (500 IU) daily intake per person; (S4) cholecalciferol fortification level increased to $50 \mu \mathrm{g}$ (2000 IU) daily intake per person; (S5) Ca fortification level decreased to $0 \mathrm{mg}$ daily intake per person; (S6) Ca fortification level increased to $1000 \mathrm{mg}$ daily intake per person; (S7) all fortification programme-related costs 
except the recurrent production costs decreased by $-50 \%$; (S8) all fortification programme-related costs except the recurrent production costs increased by $100 \%$; (S9) all input fracture probabilities decreased by $-30 \%$; (S10) all input fracture probabilities increased by $30 \%$; (S11) the time in a nursing home attributable to the fracture decreased to 0.5 years; (S12) the time in a nursing home attributable to the fracture increased to $2 \cdot 0$ years; (S13) the lower relative risk value of the $95 \% \mathrm{CI}$ applied to model the treatment effect; (S14) the upper relative risk value of the $95 \%$ CI applied to model the treatment effect; (S15) the same treatment effect assumed for men aged 65 years and older as for women aged 65 years and older; (S16) adherence level decreased to $50 \%$; and (S17) adherence level increased to $100 \%$. We assumed that the parameter variations in (S3-S7) affect only the cost of intervention and not the treatment effect.

\section{Results}

\section{Base case}

The results of the base case analysis are presented in Table 5. The total costs of the vitamin D and Ca foodfortification programme amounted to $€ 41$ million per year: $€ 33.1$ million for cholecalciferol and $\mathrm{Ca}, € 3.3$ million for marketing and education activities, €2.9 million for food control and monitoring, and $€ 2 \cdot 1$ million for other programme-specific recurrent production costs. On the other hand, €356 million in the cost of fractures were saved per year. The largest cost savings ( $43 \%$ of the total cost savings) came from prevented hip fractures, with savings of $€ 152.5$ million, while the other cost savings came from averted fractures of the humerus ( $€ 61.8$ million, $17 \%$ ), clinical vertebral ( $€ 46.4$ million, $13 \%$ ), pelvis (€39.2 million, $11 \%$ ), wrist (€34.4 million, $10 \%$ ) and other femur (€21.9 million, 6\%). The intervention would have an annual net savings potential of $€ 315$ million, so the estimated benefit-cost ratio of a vitamin $\mathrm{D}$ and Ca

Table 5 Base case results of costs and fracture numbers for the scenarios of no fortification and voluntary fortification

\begin{tabular}{lcrr}
\hline & \multicolumn{2}{c}{ Scenario } & \\
\cline { 2 - 3 } Category & No fortification & Fortification & Increment \\
\hline Costs $(€$, millions $)$ & & & \\
$\quad$ Fracture costs & $3581 \cdot 3$ & $3225 \cdot 2$ & $-356 \cdot 1$ \\
$\quad$ Intervention costs & - & 41.3 & $41 \cdot 3$ \\
$\quad$ Total costs & $3581 \cdot 3$ & $3266 \cdot 5$ & -314.8 \\
Fractures $(n)^{\star}$ & & & \\
$\quad$ Hip & 100582 & 90440 & -10143 \\
Other femur & 11356 & 10052 & -1304 \\
Clinical vertebral & 72812 & 66244 & -6568 \\
$\quad$ Wrist & 76489 & 67708 & -8781 \\
$\quad$ Humerus & 50973 & 45122 & -5852 \\
$\quad$ Pelvis & 35354 & 31295 & -4059 \\
$\quad$ Total fractures & 347566 & 310861 & -36705 \\
\hline
\end{tabular}

${ }^{*}$ Fractures in the German female population aged 65 years and older. food-fortification programme for Germany was 9:1. Our model estimated that the fortification programme would prevent 36705 fractures in the target population per year.

\section{Projections}

Our projections for the years 2025 and 2050 showed that the annual net savings from a vitamin D and Ca foodfortification programme in Germany would increase in the future. The annual net savings were expected to increase by $€ 17$ million to $€ 332$ million by the year 2025 and to increase by $€ 63$ million to $€ 378$ million by the year 2050 . This increase was based on two effects. On the one hand, the gross savings potential increased because of the ageing of the German population that led to an increase of the female population aged 65 years and older who benefit from the intervention. On the other hand, the intervention costs declined because of a shrinking overall population.

\section{Sensitivity analysis}

The results of the deterministic sensitivity analyses are shown in Fig. 1 as the percentage difference between the annual net savings from the base case analysis and each univariate sensitivity analysis. The largest change in annual net savings occurred when varying the relative risk due to food fortification (S13/S14; $110 \%$ increase in net savings/ $-143 \%$ decrease in net savings). Applying modified fracture incidence rates (S9/S10) resulted in a change in the annual net savings of $-34 \%$ and $34 \%$, respectively. Assuming the same treatment effect for men as for women (S15) increased the annual net savings by 33\%. The sensitivity analysis also showed that reducing the adherence level to $50 \%$ (S16) reduced the annual net savings by $-44 \%$, while increasing the adherence level to $100 \%$ (S17) increased the net savings by $25 \%$. The results appeared to be largely insensitive to variations in the cost parameters (S1/S2 and S7/S8) and changes in fortification levels for both cholecalciferol (S3/S4) and Ca (S5/S6).

\section{Discussion}

\section{Summary of results and comparison with the literature}

The present study suggests that a population-wide voluntary vitamin D and Ca food-fortification programme would save the German health and social care systems approximately €315 million per year by helping to prevent osteoporotic fractures in the female population aged 65 years and older. The study also finds that the annual cost savings would increase by $20 \%$ by the year 2050 , driven by an ageing population. These results could be useful for health policy makers especially in Germany given the high prevalence of vitamin D and Ca deficiency, the projected increase in the incidence of osteoporotic 
RR due to food fortification upper/lower $95 \% \mathrm{Cl}$ (S13/S14)

Change in fracture incidence rates $-/+30 \%$ (S9/S10)

Same treatment effect for men $>65$ years as for women $>65$ years (S15)

Change in adherence rates 50\%/100\% (S16/S17)

Change in fracture attributable time in nursing home

$0.5 / 2.0$ years $(\mathrm{S} 11 / \mathrm{S} 12)$

Change in Ca fortification levels $0 / 1000 \mathrm{mg}$ (S5/S6)

Change in cholecalciferol and Ca prices $-50 \% /+100 \%$ (S1/S2)

Change in cholecalciferol fortification levels $12 \cdot 5 / 50 \mu \mathrm{g}$ (500/2000 IU) (S3/S4)

Change in all programme-related costs except recurrent production costs $-50 \% /+100 \%(\mathrm{~S} 7 / \mathrm{S} 8)$

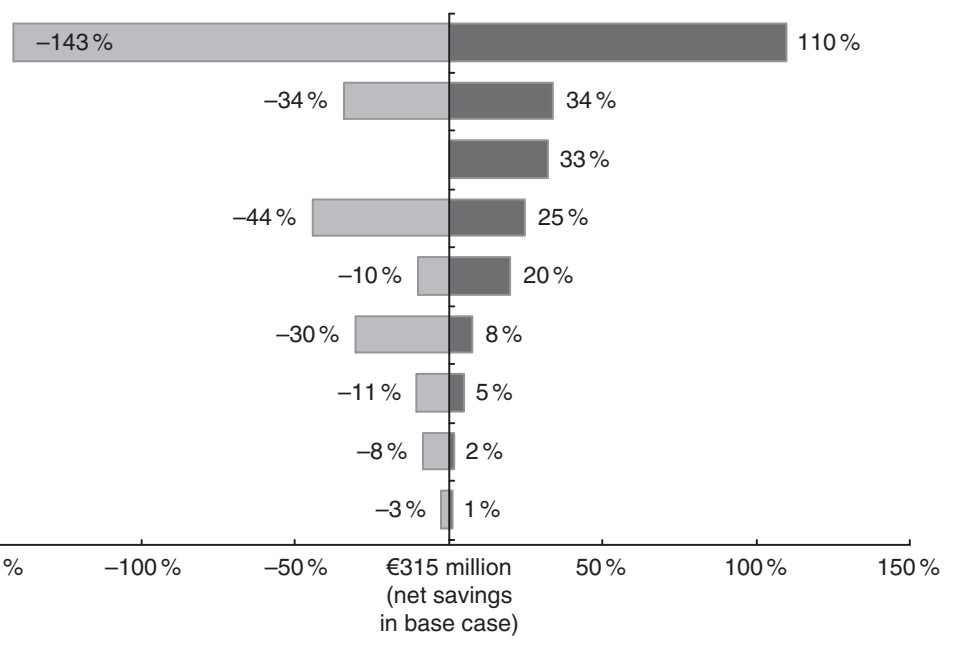

Fig. 1 Results of the deterministic sensitivity analyses. Percentage difference between the annual net savings from the base case analysis and each univariate sensitivity analysis (RR, relative risk)

fractures and the growing importance of economic evaluations in public health decision making ${ }^{(24)}$. At the same time, our study's approach may serve as a blueprint for similar evaluations in other countries that face similar problems.

Our results are in line with previous findings from Grant et al., who concluded that a vitamin D food-fortification programme is a prevention strategy that would save significant costs ${ }^{(52)}$. We estimated a benefit-cost ratio of 9:1 for Germany, while Grant et al. projected a benefitcost ratio of $20: 1$ for the European scenario ${ }^{(52)}$. The significantly higher benefit-cost ratio estimated by Grant et al. may be explained by the fact that they also considered the cost savings from the prevention of nonskeletal diseases like cancer, CVD, diabetes mellitus and infectious diseases. In contrast to their approach, we focused only on the potential cost savings from prevented osteoporotic fractures. We adopted this conservative approach because the role of vitamin $\mathrm{D}$ and $\mathrm{Ca}$ in musculoskeletal health is well recognized ${ }^{(6)}$, whereas the association of vitamin D status with non-skeletal diseases including cancer ${ }^{(53)}, \mathrm{CVD}^{(54)}$, diabetes mellitus ${ }^{(55)}$, etc. is based largely on observational and ecological studies ${ }^{(56)}$, with only few randomized controlled trials and metaanalyses on which to base economic evaluations ${ }^{(52,57)}$. Including potential benefits from the prevention of nonskeletal diseases would make the fortification approach even more beneficial. According to Zittermann, the overall cost savings for Germany when non-skeletal diseases are included would be $€ 37.5$ billion per year ${ }^{(58)}$.

The intervention costs are mainly comprised of the cost of cholecalciferol and Ca. However, our sensitivity analysis showed that the results are largely insensitive to changes in the prices and fortification levels of cholecalciferol and Ca (Fig. 1) because the total annual intervention costs of $€ 41$ million are low compared with the total estimated cost savings of $€ 356$ million per year. Therefore, changes in any of the cost categories have little effect. The limited intervention costs are driven primarily by the low prices for cholecalciferol and Ca. There are two reasons for the significant price difference to retail prices. First, cholecalciferol and $\mathrm{Ca}$ would be purchased in a raw material form that is needed for industrial food processing. Second, the raw materials are purchased in large quantities to supply the entire German population. The food-fortification strategy would probably not be cost saving if retail prices were used for the intervention cost calculation instead, as is often done in evaluations of supplementation strategies $(24,59,60)$.

The estimated investment in marketing and education activities of $€ 3.3$ million per year might be considered too low in the context of a Western country, especially since raising consumers' awareness to ensure their acceptance is central to the success of a food-fortification programme ${ }^{(40)}$. However, $€ 3 \cdot 3$ million per year is the longterm average spending for marketing and education. While the required investment in consumer education might be significantly higher directly prior to and after programme implementation, it is likely to decline once acceptance of the fortified foods is established. Moreover, in light of the large potential for net savings ( $€ 315$ million annually) there is significant room to increase the average spending for consumer education without changing the positive benefit-cost ratio of the food-fortification strategy.

Many food companies have shown increasing interest in participating in the rapidly growing market of functional foods $^{(61)}$. The opportunity to fortify foods with vitamin D and $\mathrm{Ca}$ would open the window for the introduction of new functional food products and would offer new sales and marketing opportunities for the food industry ${ }^{(61)}$. Therefore, chances are high that a large part of the cost of the ingredients cholecalciferol and Ca would be covered by the food industry, which would make the intervention strategy even more favourable from a public health system perspective. 


\section{Adverse effects}

Before undertaking a vitamin D and Ca food-fortification programme, policy makers should take into consideration the potential for adverse health effects from excessive intake of vitamin D- and Ca-fortified food. The primary concern in the case of excessive vitamin D intake is the risk of hypercalcaemia as a consequence of vitamin D intoxication $^{(62)}$, but most cases of vitamin D toxicity occur at serum 25-hydroxyvitamin D levels of more than 500 $\mathrm{nmol} / \mathrm{l}^{(62)}$, which are highly unlikely to happen at the programme's target fortification levels ${ }^{(13,44)}$. As for Ca, there is ongoing controversial discussion about the increased risk of CVD from excessive Ca intake ${ }^{(41,63,64)}$, but the likelihood of excessive intake from Ca-fortified food is relatively low ${ }^{(14)}$. Liberal fortification practices have been in place in a number of countries for many years with no reported adverse health effects ${ }^{(65)}$. In addition, Flynn et al. showed that, even in the small proportion of individuals who exceed the UL for vitamin D and $\mathrm{Ca}$ intakes, there is little risk of adverse effects ${ }^{(66-68)}$.

The vitamin D and Ca fortification levels in our study comply with the recommendations of the DVO (additional daily cholecalciferol intake of $20 \mu \mathrm{g}$ (800 IU) and total daily Ca intake of $1000 \mathrm{mg})^{(41)}$ and were chosen such that the total daily vitamin D and Ca intakes of the German adult population would remain well below the critical thresholds of $100 \mu \mathrm{g}(4000 \mathrm{IU})^{(41,69)}$ and $2500 \mathrm{mg}^{(43)}$, respectively. There would also be very limited risk of exceeding the UL in population groups like infants aged 12 months and younger (UL: $25 \mu \mathrm{g}$ (1000 IU) for vitamin D and $1000 \mathrm{mg}$ for $\mathrm{Ca}$ ), young children aged 1-10 years (UL: $50 \mu \mathrm{g}(2000 \mathrm{IU}) / 2500 \mathrm{mg}$ ), and pregnant and breastfeeding women (UL: $100 \mu \mathrm{g} \quad$ (4000 IU)/2500 $\mathrm{mg})^{(42,43,69,70)}$. In light of the discussion about the potential for increased risk of $\mathrm{CVD}^{(64)}$, we refrained from choosing higher $\mathrm{Ca}$ fortification levels than were necessary to fulfil the DVO's recommendations for daily intake ${ }^{(41)}$. Should future research provide evidence that higher $\mathrm{Ca}$ intake levels are safe and conducive to reducing the risk of fracture further, an increase in the Ca fortification level could be considered without influencing the economically positive character of the food-fortification strategy. For example, our sensitivity analysis shows that a fortification level of $1000 \mathrm{mg}$ (five times the currently chosen fortification level) would reduce the annual net cost savings by $-30 \%$, but the strategy would remain cost saving. In summary, population-wide vitamin $\mathrm{D}$ and Ca food fortification at the proposed fortification levels carries only limited risk of adverse effects ${ }^{(52,67,68)}$.

\section{Design of intervention strategy}

Alternative intervention strategies

Food fortification provides a valuable alternative to lifetime supplementation as a preventive strategy to control vitamin D and Ca deficiency in an entire population ${ }^{(38,71)}$.
A number of arguments speak in favour of the foodfortification strategy. First, supplementation for the entire population is difficult to implement logistically ${ }^{(10)}$. Second, there is a lack of medication adherence in the case of long-term treatment, as many studies of chronically ill infants and adolescents have shown ${ }^{(72)}$. Third, in times of economic constraint, physician visits and the prescription of supplements at retail prices for the entire population would impose a substantial financial burden on the German health-care system. While supplementation remains an effective measure for ensuring the vitamin D and Ca supply of risk groups ${ }^{(73)}$, food fortification is more suitable for ensuring a basic supply of vitamin D and Ca for the entire German population ${ }^{(71,74)}$.

\section{Characteristics of the food-fortification programme}

Some may argue that a mandatory food-fortification programme would be more effective than a voluntary programme because it would ensure a higher adherence level of close to $100 \%$. In fact, our sensitivity analysis showed that $100 \%$ adherence would increase the cost savings by a fifth (Fig. 1), which speaks in favour of a mandatory approach. However, the downside of a mandatory intervention is that it is a much stronger regulatory intervention, which results in a loss of consumer choice $^{(75)}$. Health policy makers would have to consider the negative utility impact of such loss of consumer choice when defining the regulatory characteristics of a foodfortification programme ${ }^{(75)}$. Two other arguments that speak in favour of a voluntary approach are that voluntary fortification practices have successfully improved the intake and status of various micronutrients in population groups across Europe ${ }^{(76)}$ and that the large majority of German consumers would be willing to consume vitamin D-fortified food $^{(40)}$. Therefore, a voluntary fortification programme is a viable alternative to a mandatory approach.

Another frequently discussed characteristic of fortification programmes is the amount and type of carrier products used. We selected bread as an exemplary single carrier product, because bread fulfils the essential requirements of a suitable carrier ${ }^{(44)}$. First, bread is homogeneously consumed across all social classes and age groups and shows no declining consumption in the elderly, which is especially important in the case of osteoporosis prevention $^{(12,44)}$. Second, bread is not a peak product as it is consumed constantly throughout the year ${ }^{(12)}$. Third, the technical implementation and subsequent monitoring of flour fortification are feasible and practicable ${ }^{(77,78)}$. The arguments in favour of fortifying at low concentration a wide variety of foods suggest that this approach minimizes the share of non-consumers (e.g. because of intolerance of a specific food or ingredient, or people following special diets such as vegans $)^{(14,36)}$ and reduces the risk of intoxication ${ }^{(44)}$. A variety of foods are available for vitamin D and Ca fortification in Germany, including milk and juice, which have already successfully 
been fortified with vitamin D and $\mathrm{Ca}^{(36,45,48,76)}$. Even if the cost of ingredients and fortification increased in the case of alternative carrier products, the principal advantages of the programme in Germany would remain unchanged, as our sensitivity analysis shows that changes in cost have little influence on the results (Fig. 1).

\section{Limitations and future research}

There are a number of limitations to the approach adopted in our study. First, our study focused on potential cost savings from the prevention of fractures in the female population aged 65 years and over in Germany, although there are several other benefits associated with increased vitamin D and Ca levels, but evidence for these benefits is currently limited $^{(52)}$. The exclusion of other benefits may have underestimated the potential cost savings, so the base case results are conservative. Should future research substantiate the relationship between vitamin D and Ca levels and the incidence of other diseases, those diseases could be included in the calculation of potential cost savings.

Second, the fracture risk reduction from vitamin D and Ca intervention was derived from a Cochrane review from Avenell et al. ${ }^{(13)}$. However, evidence of the extent of the risk reduction varies ${ }^{(13,79)}$. There is a clear need for future research in this direction, especially in the form of multicentre randomized controlled trials ${ }^{(52,80)}$.

Third, we did not include any adverse effects. Even though there is only limited risk of adverse effects ${ }^{(52,67,68)}$, their incidence would increase costs and result in the base case's results being overestimated.

Fourth, we used an adherence level of $82 \%$ for the base case reported in Sandmann et al. ${ }^{(40)}$. However, this value is hypothetical and may not translate into real adherence, so real adherence levels could be lower or higher ${ }^{(40)}$. Therefore, this assumption may overestimate or underestimate the potential cost savings of a voluntary fortification programme.

Fifth, we did not consider indirect costs in our analysis of fracture-related unit costs, as we assumed that no productivity loss is incurred because most of the target group is no longer employed. While this assumption may hold true for the majority of the German population aged 65 years and older, some in this group (e.g. self-employed workers) might still be working. Therefore, indirect costs may be incurred as a result of a fracture that are not considered in our study, and the potential cost savings may be underestimated.

Sixth, we selected bread as an exemplary carrier product for vitamin D and Ca food fortification. However, consumers' acceptance of fortified foods also depends on the type of food carrier ${ }^{(71,81)}$. Future research should determine which food products would see the highest level of acceptance as a carrier for vitamin $\mathrm{D}$ and $\mathrm{Ca}$ in Germany $^{(40)}$.

Seventh, we did not account for overage of manufacturers in the bread production process and food waste by retailers as such data were not available. Such practices increase the amount of ingredients required and result in additional costs. Not considering these costs may have resulted in overestimating the potential cost savings.

\section{Conclusions}

Our findings indicate that vitamin $\mathrm{D}$ and $\mathrm{Ca}$ food fortification is an economically beneficial preventive health strategy that has the potential to reduce the future health burden of osteoporotic fractures in Germany. The intervention would cost little while offering substantial cost savings for the German health and social care systems. The implementation of a vitamin D and Ca foodfortification programme should be a high priority for German health policy makers.

\section{Acknowledgements}

Financial support: This research received no specific grant from any funding agency in the public, commercial or notfor-profit sectors. Conflict of interest: None. Authorship: A.S. conceived and designed the study, acquired and analysed the data, interpreted the results and wrote the paper. F.Bl. participated in the study design, data analysis and interpretation, and reviewed and revised the manuscript. M.A., F.Ba. and H-.H.K. jointly provided overall supervision, support and advice on the study design and data analysis, and reviewed and revised the manuscript. All authors read and approved the final manuscript. Ethics of buman subject participation: Not applicable.

\section{References}

1. Svedbom A, Hernlund E, Ivergård $M$ et al. (2013) Osteoporosis in the European Union: a compendium of country-specific reports. Arch Osteoporos 8, 1-218.

2. Bleibler F, Konnopka A, Benzinger P et al. (2013) The health burden and costs of incident fractures attributable to osteoporosis from 2010 to 2050 in Germany - a demographic simulation model. Osteoporos Int 24, 835-847.

3. Hiligsmann M, Ethgen O, Richy F et al. (2008) Utility values associated with osteoporotic fracture: a systematic review of the literature. Calcif Tissue Int 82, 288-292.

4. Johnell O, Kanis J, Oden A et al. (2004) Mortality after osteoporotic fractures. Osteoporos Int 15, 38-42.

5. Morin S, Lix L, Azimaee M et al. (2011) Mortality rates after incident non-traumatic fractures in older men and women. Osteoporos Int 22, 2439-2448.

6. von Domarus C, Brown J, Barvencik F et al. (2011) How much vitamin D do we need for skeletal health? Clin Orthop Relat Res 469, 3127-3133.

7. Holick M (2006) High prevalence of vitamin D inadequacy and implications for health. Mayo Clin Proc 81, 353-373.

8. Hossein-nezhad A \& Holick MF (2013) Vitamin D for health: a global perspective. Mayo Clin Proc 88, 720-755.

9. Palacios C \& Gonzalez L (2013) Is vitamin D deficiency a major global public health problem? J Steroid Biochem Mol Biol 144, 138-145. 
10. Brown J, Amling M \& Barvencik F (2011) Possibilities for improving the vitamin D status of the German population (in German). Mineralstoffwechsel 18, 104-109.

11. Ringe JD \& Kipshoven C (2012) Vitamin D-insufficiency - an estimate of the situation in Germany. Dermatoendocrinology 4, 77-85.

12. Max Rubner-Institute, Bundesforschungsinstitut für Ernährung und Lebensmittel (2008) National Nutritional Survey II - Part 2 (in German). http://www.bmelv.de/Shared Docs/Downloads/Ernaehrung/NVS_ErgebnisberichtTeil2.pdf (accessed May 2015).

13. Avenell A, Mak J \& O'Connell D (2014) Vitamin D and vitamin $\mathrm{D}$ analogues for preventing fractures in postmenopausal women and older men. Cochrane Database Syst Rev 4, CD000227.

14. Kiely M \& Black L (2012) Dietary strategies to maintain adequacy of circulating 25-hydroxyvitamin D concentrations. Scand J Clin Lab Invest Suppl 72, 14-23.

15. Pietinen P, Männistö S, Valsta L et al. (2010) Nutrition policy in Finland. Public Health Nutr 13, 901-906.

16. Calvo M \& Whiting SJ (2013) Survey of current vitamin D food fortification practices in the United States and Canada. J Steroid Biochem Mol Biol 136, 211-213.

17. Black LJ, Seamans KM, Cashman KD et al. (2012) An updated systematic review and meta-analysis of the efficacy of vitamin D food fortification. J Nutr 142, 1102-1108.

18. Federal Ministry of Justice (1942) Regulation on vitaminised foods (in German). http://www.gesetze-im-internet.de/ bundesrecht/lmvitv/gesamt.pdf (accessed May 2015).

19. Federal Ministry of Justice (1963) Regulation on dietary foods (in German). http://www.gesetze-im-internet.de/ bundesrecht/di_tv/gesamt.pdf (accessed May 2015).

20. European Parliament \& the Council of the European Union (2006) Regulation (EC) No $1925 / 2006$ of the European Parliament and of the Council of 20 December 2006 on the addition of vitamins and minerals and of certain other substances to foods. Official Journal of the European Union 1925/2006, L404/426-L404/438.

21. European Food Safety Authority (2006) Tolerable Upper Intake Levels for Vitamins and Minerals. Parma: EFSA; available at http://www.efsa.europa.eu/sites/default/files/ efsa_rep/blobserver_assets/ndatolerableuil.pdf

22. Willis M (2002) The health economics of calcium and vitamin $\mathrm{D}_{3}$ for the prevention of osteoporotic hip fractures in Sweden. Int J Technol Assess Health Care 18, 791-807.

23. Lee R, Weber T \& Colón-Emeric C (2013) Comparison of cost-effectiveness of vitamin D screening with that of universal supplementation in preventing falls in communitydwelling older adults. J Am Geriatr Soc 61, 707-714.

24. Hiligsmann M, Ben Sedrine W, Bruyere O et al. (2014) Cost-effectiveness of vitamin D and calcium supplementation in the treatment of elderly women and men with osteoporosis. Eur J Public Health 25, 20-25.

25. Fleurence R (2004) Cost-effectiveness of fracture prevention treatments in the elderly. Int J Technol Assess Health Care 20, 184-191.

26. Federal Statistical Office of Germany (2009) Population projection. https://www.destatis.de/EN/FactsFigures/Society State/Population/PopulationProjection/PopulationProjection. html (accessed February 2015).

27. Kanis J, Johnell O, Oden A et al. (2000) Risk of hip fracture according to the World Health Organization criteria for osteopenia and osteoporosis. Bone 27, 585-590.

28. Johnell O \& Kanis J (2005) Epidemiology of osteoporotic fractures. Osteoporos Int 16, Suppl. 2, S3-S7.

29. Bleibler F, Rapp K, Jaensch A et al. (2014) Expected lifetime numbers and costs of fractures in postmenopausal women with and without osteoporosis in Germany: a discrete event simulation model. BMC Health Serv Res 14, 284.
30. Federal Statistical Office of Germany (2011) Deep stratified diagnosis-data from female and male inpatients 2009 (in German). https://www.destatis.de/GPStatistik/receive/ DEHeft_heft_00022730 (accessed February 2015).

31. Rapp K, Becker C, Cameron I et al. (2012) Femoral fracture rates in people with and without disability. Age Ageing $\mathbf{4 1}$, 653-658.

32. Benzinger P, Becker C, Kerse N et al. (2013) Pelvic fracture rates in community-living people with and without disability and in residents of nursing homes. J Am Med Dir Assoc 14, 673-678.

33. Osnes E, Lofthus C, Meyer H et al. (2004) Consequences of hip fracture on activities of daily life and residential needs. Osteoporos Int 15, 567-574.

34. Morin S, Lix L, Azimaee M et al. (2012) Institutionalization following incident non-traumatic fractures in communitydwelling men and women. Osteoporos Int $\mathbf{2 3}$, 2381-2386.

35. Eurostat (2014) HICP - inflation rate. http://ec.europa. $\mathrm{eu} /$ eurostat $/ \mathrm{tgm} / \mathrm{table}$. do?tab=table\&init $=1 \&$ language $=\mathrm{en} \&$ pcode $=$ tec00118\&plugin $=1$ (accessed March 2015).

36. Spiro A \& Buttriss J (2014) Vitamin D: an overview of vitamin D status and intake in Europe. Nutr Bull 39, 322-350.

37. Horton S (2006) The economics of food fortification. J Nutr 136, 1068-1071.

38. Darnton-Hill I \& Nalubola R (2002) Fortification strategies to meet micronutrient needs: successes and failures. Proc Nutr Soc 61, 231-241.

39. Federal Ministry of Justice (1989) Regulation amending regulations on iodised table salt (in German). http://www.bgbl.de/ xaver/bgbl/start.xav?start=//*[@attr_id=\%27bgbl189s1123.pdf \%27]\#_bgbl_\%2F\%2F*[\%40attr_id\%3D\%27bgbl189s1123.pdf \%27]_1446500153135 (accessed May 2015).

40. Sandmann A, Brown J, Mau G et al. (2015) Acceptance of vitamin D-fortified products in Germany - a representative consumer survey. Food Qual Prefer 43, 53-62.

41. Dachverband Osteologie eV (2014) DVO guidelines 2014 for prevention, diagnosis and treatment of osteoporosis for men aged 60 years and above and postmenopausal women (in German). http://www.dv-osteologie.org/dvo_leitlinien/ osteoporose-leitlinie-2014 (accessed June 2015).

42. Institute of Medicine (2011) Dietary Reference Intakes for Calcium and Vitamin D. Washington, DC: The National Academies Press.

43. European Food Safety Authority (2012) Scientific Opinion on the Tolerable Upper Intake Level of Calcium. Parma: EFSA; available at http://www.efsa.europa.eu/sites/default/ files/scientific_output/files/main_documents/2814.pdf

44. Brown J, Sandmann A, Ignatius A et al. (2013) New perspectives on vitamin $\mathrm{D}$ food fortification based on a modeling of 25(OH)D concentrations. Nutr J 12, 151.

45. Madsen KH, Rasmussen LB, Andersen R et al. (2013) Randomized controlled trial of the effects of vitamin $\mathrm{D}_{3}$ fortified milk and bread on serum 25-hydroxyvitamin D concentrations in families in Denmark during winter: the VitmaD study. Am J Clin Nutr 98, 374-381.

46. Costan A, Vulpoi C \& Mocanu V (2014) Vitamin D fortified bread improves pain and physical function domains of quality of life in nursing home residents. J Med Food 17, 625-631.

47. Mocanu V, Stitt PA, Costan AR et al. (2009) Long-term effects of giving nursing home residents bread fortified with $125 \mu \mathrm{g}$ (5000 IU) vitamin $\mathrm{D}_{3}$ per daily serving. Am J Clin Nutr 89, 1132-1137.

48. Nissen J, Vogel U, Ravn-Haren G et al. (2014) Real-life use of vitamin $\mathrm{D}_{3}$-fortified bread and milk during a winter season: the effects of CYP2R1 and GC genes on 25-hydroxyvitamin D concentrations in Danish families, the VitmaD study. Genes Nutr 9, 413. 
49. US Agency of International Development \& DSM (2015) Fortification basics. http://www.dsm.com/content/dam/dsm/ nip/en_US/documents/stability.pdf (accessed June 2015).

50. Fiedler J, Sanghvi T \& Saunders M (2008) A review of the micronutrient intervention cost literature: program design and policy lessons. Int J Health Plann Manage 23, 373-397.

51. Federal Ministry of Food and Agriculture (2014) Every eighth food product that we buy is thrown away (in German). https://www.zugutfuerdietonne.de/fileadmin/_migrated/ content_uploads/Studie_Lebensmittelabfaelle_Kurzfassung 02.pdf (accessed March 2015).

52. Grant W, Cross H, Garland C et al. (2009) Estimated benefit of increased vitamin D status in reducing the economic burden of disease in Western Europe. Prog Biophys Mol Biol 99, 104-113.

53. Garland CF, Garland FC, Gorham ED et al. (2006) The role of vitamin D in cancer prevention. Am J Public Health 96 , 252-261.

54. Drechsler C, Pilz S, Obermayer-Pietsch B et al. (2010) Vitamin D deficiency is associated with sudden cardiac death, combined cardiovascular events, and mortality in haemodialysis patients. Eur Heart J 31, 2253-2261.

55. Hypponen E, Läärä E, Reunanen A et al. (2001) Intake of vitamin $\mathrm{D}$ and risk of type 1 diabetes: a birth-cohort study. Lancet 358, 1500-1503.

56. Pludowski P, Holick MF et al. (2013) Vitamin D effects on musculoskeletal health, immunity, autoimmunity, cardiovascular disease, cancer, fertility, pregnancy, dementia and mortality - a review of recent evidence. Autoimmun Rev 12, 976-989.

57. Heaney R (2014) Guidelines for optimizing design and analysis of clinical studies of nutrient effects. Nutr Rev $\mathbf{7 2}$, 48-54.

58. Zittermann A (2010) The estimated benefits of vitamin D for Germany. Mol Nutr Food Res 54, 1164-1171.

59. Nshimyumukiza L, Durand A, Gagnon M et al. (2013) An economic evaluation: simulation of the cost-effectiveness and cost-utility of universal prevention strategies against osteoporosis-related fractures. J Bone Miner Res 28, 383-394.

60. Zarca K, Durand-Zaleski I, Roux C et al. (2014) Cost-effectiveness analysis of hip fracture prevention with vitamin D supplementation: a Markov micro-simulation model applied to the French population over 65 years old without previous hip fracture. Osteoporos Int 25, 1797-1806

61. Siró I, Kápolna E, Kápolna B et al. (2008) Functional food. Product development, marketing and consumer acceptance - a review. Appetite 51, 456-467.

62. Hathcock JN, Shao A, Vieth R et al. (2007) Risk assessment for vitamin D. Am J Clin Nutr 85, 6-18.

63. Li K, Kaaks R, Linseisen J et al. (2012) Associations of dietary calcium intake and calcium supplementation with myocardial infarction and stroke risk and overall cardiovascular mortality in the Heidelberg cohort of the European Prospective Investigation into Cancer and Nutrition study (EPIC-Heidelberg). Heart 98, 920-925.

64. Bolland M, Avenell A, Baron J et al. (2010) Effect of calcium supplements on risk of myocardial infarction and cardiovascular events: meta-analysis. BMJ 341, c3691.
65. Meltzer H, Aro A, Andersen $\mathrm{N}$ et al. (2003) Risk analysis applied to food fortification. Public Health Nutr $\mathbf{6}$, 281-291.

66. Flynn A, Hirvonen T, Mensink GBM et al. (2009) Intake of selected nutrients from foods, from fortification and from supplements in various European countries. Food Nutr Res 2009, 53.

67. Holick M (2015) Vitamin D is not as toxic as was once thought: a historical and an up-to-date perspective. Mayo Clin Proc 90, 561-564.

68. Dudenkov D, Yawn B, Oberhelman S et al. (2015) Changing incidence of serum 25-hydroxyvitamin $\mathrm{D}$ values above $50 \mathrm{ng} / \mathrm{ml}$ : a 10-year population-based study. Mayo Clin Proc 90, 577-586.

69. European Food Safety Authority (2012) Scientific Opinion on the Tolerable Upper Intake Level of Vitamin D. Parma: EFSA; available at http://www.efsa.europa.eu/sites/default/ files/scientific_output/files/main_documents/2813.pdf

70. Holick M, Binkley N, Bischoff-Ferrari H et al. (2011) Evaluation, treatment, and prevention of vitamin D deficiency: an Endocrine Society clinical practice guideline. J Clin Endocrinol Metab 96, 1911-1930.

71. Howson CP, Kennedy ET \& Horwitz A (1998) Prevention of Micronutrient Deficiencies: Tools for Policymakers and Public Health Workers. Washington, DC: National Academies Press.

72. Dean AJ, Walters J \& Hall A (2010) A systematic review of interventions to enhance medication adherence in children and adolescents with chronic illness. Arch Dis Child 95 , $717-723$

73. Peterlik M (2012) Vitamin D insufficiency and chronic diseases: hype and reality. Food Funct 3, 784-794.

74. Rizzoli R, Abraham C \& Brandi M (2014) Nutrition and bone health: turning knowledge and beliefs into healthy behaviour. Curr Med Res Opin 30, 131-141.

75. Parkinson B, Goodall S \& Norman R (2013) Measuring the loss of consumer choice in mandatory health programmes using discrete choice experiments. Appl Health Econ Health Policy 11, 139-150.

76. Hennessy Á, Walton J \& Flynn A (2013) The impact of voluntary food fortification on micronutrient intakes and status in European countries: a review. Proc Nutr Soc 72, 433-440.

77. Miller DD \& Welch RM (2013) Food system strategies for preventing micronutrient malnutrition. Food Policy 42, 115-128.

78. Natri A-M, Salo P, Vikstedt T et al. (2006) Bread fortified with cholecalciferol increases the serum 25-hydroxyvitamin $\mathrm{D}$ concentration in women as effectively as a cholecalciferol supplement. J Nutr 136, 123-127.

79. Bischoff-Ferrari HA, Willett WC, Orav EJ et al. (2012) A pooled analysis of vitamin D dose requirements for fracture prevention. $N$ Engl J Med 367, 40-49.

80. Scragg R (2011) Vitamin D and public health: an overview of recent research on common diseases and mortality in adulthood. Public Health Nutr 14, 1515-1532.

81. Jonas M \& Beckmann S (1998) Functional Foods: Consumer Perceptions in Denmark and England. MAPP Working Paper no. 55. Aarhus: Centre for Market Surveillance, Research and Strategy for the Food Sector; available at http://pure.au.dk/portal/files/91/wp55.pdf 